Check for updates

Cite this: RSC Adv., 2018, 8, 12179

\title{
Eco-friendly synthesis of graphene-chitosan composite hydrogel as efficient adsorbent for Congo red $\uparrow$
}

\begin{abstract}
Sakineh Omidi and Ali Kakanejadifard (iD *
A simple approach was utilized to synthesize graphene/chitosan-based hydrogel using glutaraldehyde as crosslinking agent in room temperature. The composite aerogel was used for removal of cationic and anionic dyes from aqueous solution. It showed high adsorption capacity towards Congo red as an anionic dye. Adsorption experiments were performed based on various parameters, such as initial Congo red concentration, solution $\mathrm{pH}$ and contact time. The kinetics data were analyzed using four different models and the pseudo-second-order model best described the adsorption of Congo red aerogel. The Equilibrium adsorption isotherm data indicated that equilibrium data were fitted to the Langmuir isotherm. The maximum dye adsorption capacity calculated from the Langmuir isotherm equation was $384.62 \mathrm{mg} \mathrm{g}^{-1}$. Moreover, the aerogel was stable and easily recovered, and adsorption capacity was about $100 \%$ of the initial saturation adsorption capacity after being used three times.
\end{abstract}

Received 17th January 2018

Accepted 22nd March 2018

DOI: $10.1039 / \mathrm{c} 8 \mathrm{ra00510a}$

rsc.li/rsc-advances

attached to heavy metals ions ${ }^{16}$ and positively charged organic compounds. ${ }^{17}$

To utilize of the large surface area, much effort has been The discharge of waste from different dye-related industries into the water stream has been considered as a major environmental issue. ${ }^{1,2}$ Congo red (CR), an anionic diazo dye, is one of the most important azo dyes. It is highly soluble in aqueous solution and resistant to microbial biodegradation and photocatalysis due to its complex and stable aromatic molecular structure. CR is metabolized into benzidine which is a suspect carcinogen and mutagen compound. ${ }^{3,4}$ Many forms of carbonbased materials were used as the adsorbent for water purification, such as conventional activated carbon, ${ }^{5}$ carbon nanomaterials, including carbon nanotubes, ${ }^{6}$ and carbon nanofibers. ${ }^{7}$ Graphene, a single layer of two-dimensional carbon lattice, has attracted intensive interest because of its excellent mechanical, physical and chemical properties. ${ }^{8,9}$ Graphene-based materials have widespread applications in many technological fields including nanoelectronic devices, ${ }^{10}$ hydrogen storage, ${ }^{11}$ drug delivery ${ }^{12}$ and antibacterial. ${ }^{13,14}$ Graphene exhibits huge specific surface area with a theoretical value of $2630 \mathrm{~m}^{2} \mathrm{~g}^{-1}$ (ref. 15) that make it a possible candidate as dye adsorbent. Pristine graphene is hydrophobic substance and it is not a good adsorbent for many types of pollutions. Graphene oxide (GO) contains various functional groups such as hydroxyls and carboxyls in the plane or at the edge. Therefore, GO is hydrophilic and has a negative charge that could be

Faculty of Science, Department of Chemistry, Lorestan University, Khorramabad, Iran. E-mail: ali.kakanejadifard@gmail.com

$\dagger$ Electronic supplementary information (ESI) available. See DOI: 10.1039/c8ra00510a devoted to the preparation of the stable homogeneous dispersion of single-layered GO as an absorbent. ${ }^{18}$ However, high water dispersibility of GO caused that expensive separation techniques such as ultrahigh centrifugation be essential to remove the spent GO after the adsorption process. Furthermore, since GO is a nano-material and unprecipitated GO can exhibit potential toxicity to human cells, ${ }^{19,20}$ the public is concerned on their ecological and environmental risks. As a result, the practical applications of nano-dispersed GO in wastewater purification may restrict. An appropriate absorbent should have the high surface area, easy recovery, and excellent stability. Construction of graphene-based three-dimensional (3D) is a facile strategy, to achieve a good absorbent with useful properties such as large surface areas, ultralow density, easy separation and strong mechanical strength. ${ }^{21}$ GO-based hydrogels with enhanced absorption capability has been previously reported. ${ }^{22,23}$

Chitosan is a non-toxic, biodegradable and biocompatible polysaccharide. Several researchers have reported the graphene or chitosan composite hydrogels as efficient adsorbents for water purification. Chatterjee investigated the adsorption performance of chitosan (CS) hydrogel beads impregnated with nonionic and anionic surfactants,$^{24}$ cetyl trimethyl ammonium bromide ${ }^{25}$ and multiwalled carbon nanotubes ${ }^{26}$ for the removal of Congo red (CR) from aqueous solution. Li and Bai report an eco-friendly graphene oxide-chitosan (GO-CS) hydrogel as a broad-spectrum adsorbent for deletion of dyes and metal ions. ${ }^{27}$ Shang synthesized Konjac glucomannan-graphene oxide 
hydrogel and used it to adsorb methyl orange and methyl blue in aqueous solutions. ${ }^{28}$ Cheng and Zhao successfully prepared GO-biopolymer gels with bovine serum albumin, DNA, and chitosan as adsorbent for cationic dyes and metal ions. ${ }^{29}$ These and many other reports ${ }^{\mathbf{3 0 - 4 0}}$ indicated that chitosan and graphene-based material have potential utility for construction of composite material as efficient adsorbents. Some recent review articles have highlighted the application of graphene oxide nitrogen-containing derivatives or graphene 3D structures in removal of contaminants from wastewater. ${ }^{\mathbf{4 1 , 4 2}}$

In this research, first GO was converted to an aminated form with ethylenediamine (EDA). Unlike GO, the aminatedgraphene (GN) has a positive surface charge and is expected to be a good adsorbent for anionic dyes. Upon adding glutaraldehyde (Glu) to the mixture of GN and chitosan (CS), the (GNCS) hydrogel was generated rapidly. The hydrogel can simply be turned into GN-CS aerogel by freeze-drying. The aerogel was tested to remove cationic and anionic dyes from aqueous solution. After the adsorption process the GN-CS aerogel is recovered by filtration or decantation. Kinetics and isothermic models were investigated to best describe the adsorption process.

\section{Experimental}

\section{Chemicals}

All solvents and chemical reagents were purchased from Merck and Sigma-Aldrich companies. The solvents used in the reactions were analytically reagent grade. For UV-Vis experiments the purity grade solvents ( $>99.9 \%)$, were used without any additional purification. GO was prepared according to an improved method. ${ }^{43}$

\section{Instruments}

FT-IR spectra were registered on a Shimadzu 8400S spectrometer using $\mathrm{KBr}$ disc. The UV-Vis spectra were recorded with a Shimadzu 1650 spectrophotometer. Patterns of X-ray diffraction of the materials were recorded by a Halland Philips X-ray Powder Diffraction (XRD) diffractometer at a scanning speed of $2^{\circ} \mathrm{min}^{-1}$ from $10^{\circ}$ to $100^{\circ}$ (CuK, radiation, $\lambda=0.154056 \mathrm{~nm}$ ). Structure and morphology of the nanomaterials were identified using an LEO 440i Field Emission Scanning Electron Microscope (FE-SEM) under vacuum at an operating voltage of $10 \mathrm{kV}$. Energy-dispersive X-ray microanalysis (EDX) system was used to discover corresponding elements atomic numbers. Zeta potential measurements were carried out using a Nanotrac wave II Q Particle Size Analyzer equipped with a diode laser operating at $780.0 \mathrm{~nm}$.

\section{Synthesis of aminated-GO (GN)}

GN was prepared from GO according to the method reported with a few modifications. ${ }^{\mathbf{4 4 5}}$ In a typical experiment, $0.5 \mathrm{~g}$ GO was spread in $50 \mathrm{~mL} \mathrm{2-butanol} \mathrm{and} \mathrm{sonicated} \mathrm{for} 60 \mathrm{~min}$ to give a uniform brown colloidal solution. The dispersed solution was added slowly over a period of two hours to $10.0 \mathrm{~mL}$ of EDA. The excess EDA prevents cross-linking of graphene sheets. The mixture was heated to $80-85^{\circ} \mathrm{C}$ and stirred for $8 \mathrm{~h}$. Then it was cooled down to room temperature and centrifuged $(6000 \mathrm{rpm}$ for $10 \mathrm{~min}$ ). The residual solid material was washed with ethanol and centrifuged again (two times). The resultant solid was dried at room temperature.

\section{Preparation of GN-CS hydrogel}

A CS standard solution with a concentration of $1.5 \% \mathrm{w} / \mathrm{v}$ was prepared in $100.0 \mathrm{~mL}$ of $2 \%(\mathrm{v} / \mathrm{v})$ aqueous acetic acid, and stirring (450 rpm) overnight to obtain homogeneity. The $\mathrm{pH}$ of solution adjusted at $4.0 \mathrm{using}$ dilute sodium hydroxide. A $3 \% \mathrm{w} /$ $\mathrm{v}$ of GN solution was prepared by dispersing of $0.3 \mathrm{~g} \mathrm{GN}$ in $10.0 \mathrm{~mL}$ distilled water and sonicated for $60 \mathrm{~min}$. $1.0 \mathrm{~mL} \mathrm{CS}$ solution was added to $1 \mathrm{~mL}$ of GN suspension, and the mixtures were stirred for $5 \mathrm{~min}$. Under intense stirring, glutaraldehyde was added into the mixture. The gelation occurred within about $60 \mathrm{~s}$ of stirring. The obtained hydrogel was washed with deionized water, then it freeze-dried overnight to get an aerogel and preserved for further applications.

\section{Swelling investigations}

Swelling capacity of GN-CS hydrogel was examined by immersing $1.5 \mathrm{~g}$ of wet synthesized GN-CS hydrogel into $200.0 \mathrm{~mL}$ of distilled water at $25{ }^{\circ} \mathrm{C}$ for 24 hours. The swollen hydrogel was then decanted and excess water removed from surface of hydrogel and weight. The swollen GN-CS hydrogel dried at $60{ }^{\circ} \mathrm{C}$ then weighted. The adsorption capacity was calculated using eqn (1).

$$
\text { Swelling }(\mathrm{g} / \mathrm{g})=\frac{\left(m_{\mathrm{s}}-m_{\mathrm{d}}\right)}{m_{\mathrm{d}}}
$$

where, $m_{\mathrm{s}}$ and $m_{\mathrm{d}}$ are the weight of the swollen and dry hydrogel samples, respectively.

\section{Adsorption experiments}

The dye adsorption capacity was examined by placing the aerogel in aqueous dye solutions. Before adsorption process the aerogel washed with distilled water until pH of supernatant reached around 7.0. The effects of different parameters such as $\mathrm{pH}$ (4.0-10.0), initial dye concentration (5.0-500.0 $\left.\mathrm{mg} \mathrm{L}^{-1}\right)$ and contact time were studied. In a typical experiment, the optimized amount of hydrogel was added into $30.0 \mathrm{~mL}$ aqueous solution of dye solutions with determined concentration. The mixture was stirred at a speed of $300 \mathrm{rpm}$ at $25{ }^{\circ} \mathrm{C}$. At predetermined time intervals, $2.0 \mathrm{~mL}$ of sample was separated and concentrations of solutions were measured with a UV-Vis spectrophotometer at $497 \mathrm{~nm}$ and $530 \mathrm{~nm}$ for CR solution with $\mathrm{pH}=7.0,10.0$ and $\mathrm{pH}=4.0$ respectively, and the absorbance at $603 \mathrm{~nm}$ for JB solution with $\mathrm{pH}=7.0$. The percent removal $(R \%)$ of dye and the adsorption capacity $\left(q_{\mathrm{e}}\right)$ of the hydrogel in batch adsorption experiment were calculated using eqn (2) and (3) respectively.

$$
\text { Percent removal }(R \%)=\frac{\left(C_{0}-C_{t}\right)}{C_{0}} \times 100
$$




$$
\text { Adsorption capacity }\left(q_{\mathrm{e}}\right)=\frac{\left(C_{0}-C_{t}\right) \times V}{m}
$$

where $C_{0}$ and $C_{t}$ are the dye concentrations $\left(\mathrm{mg} \mathrm{L}^{-1}\right)$ at the 0 and $t \min , q_{\mathrm{e}}$ is the adsorption capacity $\left(\mathrm{mg} \mathrm{g}^{-1}\right)$ of GN-CS hydrogel, $V$ is the volume (mL) of dye solution and $m$ is the mass $(\mathrm{g})$ of the aerogel.

The kinetic experiments were carried out at $\mathrm{pH}=7.0$. $15.0 \mathrm{mg}$ of the GN-CS aerogel was added to $30.0 \mathrm{~mL}$ of the $\mathrm{CR}$ solution (concentration: $20.0 \mathrm{mg} \mathrm{L}^{-1}$ ) contained in a $100.0 \mathrm{~mL}$ beaker at room temperature. Samples of $2.0 \mathrm{~mL}$ volume were withdrawn from the reaction mixture at a pre-fixed time interval. The adsorbent particles were separated out by decantation of solution and examined for residual CR concentration using a UV-Vis spectrophotometer at $\lambda_{\max }=497 \mathrm{~nm}$. Isotherm studies were performed in a similar condition to the kinetic experiments and varying initial CR concentration of 100.0$500.0 \mathrm{mg} \mathrm{L}^{-1}$.

\section{Results and discussion}

After successful synthesis of GN-CS aerogel, it was characterized using various techniques including FT-IR, XRD, FE-SEM and EDX spectroscopy. GN-CS aerogel has a porous structure, so this 3D nanostructure provided enough space to absorbed many types of contaminations. Scheme 1 shows the general preparation procedure of the GN-CS hydrogel.

\section{Characterization of GN-CS hydrogel}

Fig. 1a displays the FT-IR spectra of GO, GN, CS, Glu, and GNCS aerogel solid samples. The FT-IR spectrum of GO showed the bands of hydrogen bonded $\mathrm{O}-\mathrm{H}\left(3100-3600 \mathrm{~cm}^{-1}\right), \mathrm{C}=\mathrm{O}$ $\left(1731 \mathrm{~cm}^{-1}\right), \quad \mathrm{C}=\mathrm{C}\left(1623 \mathrm{~cm}^{-1}\right)$ and $\mathrm{C}-\mathrm{O}\left(1222 \mathrm{~cm}^{-1}\right.$, $1053 \mathrm{~cm}^{-1}$ ). In GN spectrum a significant drop in strength of the band at $1731 \mathrm{~cm}^{-1}$ was identified compared to original GO. The occurrence of two new bands at $1635 \mathrm{~cm}^{-1}(\mathrm{C}=\mathrm{O}$ of the amide bond) and $1361 \mathrm{~cm}^{-1}$ (C-N) in the spectrum of GN indicate the complete grafting of EDA on the GO surface. ${ }^{44}$ FT-IR spectrum of chitosan, showed the absorption bands at $3360 \mathrm{~cm}$ ${ }^{-1}(\mathrm{O}-\mathrm{H}$ and $\mathrm{N}-\mathrm{H}), 2922 \mathrm{~cm}^{-1}$ and $2877 \mathrm{~cm}^{-1}$ (aliphatic C-H), $1655 \mathrm{~cm}^{-1}$ (bending vibration $\left.\mathrm{N}-\mathrm{H}\right), 1379 \mathrm{~cm}^{-1}(\mathrm{C}-\mathrm{N})$, and $1078 \mathrm{~cm}^{-1}$ (C-O). FT-IR spectrum of glutaraldehyde showed the absorption bands at $3354 \mathrm{~cm}^{-1}\left(\mathrm{O}-\mathrm{H}\right.$ of $\left.\mathrm{H}_{2} \mathrm{O}\right), 2951 \mathrm{~cm}^{-1}$ (aliphatic C-H), $2870 \mathrm{~cm}^{-1}$ and $2737 \mathrm{~cm}^{-1}(\mathrm{H}-\mathrm{CO})$ and $1718 \mathrm{~cm}^{-1}(\mathrm{HC}=\mathrm{O})$. In the FT-IR spectrum of GN-CS, the presence of absorbance bands at $1645 \mathrm{~cm}^{-1}$ indicated the formation of imine linkage. This spectrum also showed the absorption bands at $3400 \mathrm{~cm}^{-1}(\mathrm{O}-\mathrm{H}), 2943 \mathrm{~cm}^{-1}$ and $2871 \mathrm{~cm}^{-1}$ (aliphatic C-H), $1357 \mathrm{~cm}^{-1}(\mathrm{C}-\mathrm{N})$, and $1112 \mathrm{~cm}^{-1}$, $1024 \mathrm{~cm}^{-1}(\mathrm{C}-\mathrm{O})$.

XRD patterns of the GO, GN, CS, and GN-CS, between $10^{\circ}$ and $80^{\circ}$, are shown in Fig. 1 b. The specific $2 \theta$ peak of GO at $10.74^{\circ}$ corresponds to $\left(\begin{array}{lll}0 & 0 & 1\end{array}\right)$ interplanar spacing of $0.822 \mathrm{~nm}$. In the case of GN, the intense $\left(\begin{array}{lll}0 & 0 & 1\end{array}\right)$ peak decreased, while broad diffraction peaks appear at $2 \theta=25.4^{\circ}$, corresponding to the interplanar spacing of $0.35 \mathrm{~nm}$, which attributed to the $\left(\begin{array}{lll}0 & 0 & 2\end{array}\right)$ peak of graphite. Chitosan shows two peaks at $2 \theta=10.75^{\circ}$, and
$2 \theta=21.2^{\circ}$ corresponding to crystalline structure and amorphous state of chitosan, respectively. ${ }^{46} \mathrm{GN}-\mathrm{CS}$ indicated only a broad peak between $2 \theta=20-30^{\circ}$. This peak is like to that of GN, consequential from the remainder stacked GN sheets in the composite. The characteristic peaks of chitosan are not detected in the XRD patterns of GN-CS aerogel, showing that CS chains are well spread on the GO sheets. The absence of the diffraction peak at $2 \theta \approx 10.75^{\circ}$ in XRD pattern of GN-CS shows that formation of hydrogel has a heavy effect on the crystal structure of the GN and CS.

FE-SEM images were used for characterization of the structure of the GN-CS hydrogel. FE-SEM images of GN-CS aerogel are shown in Fig. 2a-d which indicated GN-CS aerogel has a well-defined and interrelated 3D porous network microstructure with pore sizes in the range of 1-2 micrometers. 3D network construction happened owing to the reaction between glutaraldehyde molecules and the amine group in chitosan and GN. This imine reaction results in cross-linking of GN nanosheets and polymer chains and finally hydrogel formation. The smaller pores with sized in the range of $80-250 \mathrm{~nm}$ can be seen (Fig. 2c and d). Energy dispersive X-ray spectroscopy (EDX) spectrum shows that GN-CS contains three kinds of elements $\mathrm{C}, \mathrm{O}$, and $\mathrm{N}$ (Fig. 2e). The elemental maps of $\mathrm{C}, \mathrm{O}$, and $\mathrm{N}$ in GNCS are shown in Fig. $2 \mathrm{f}$.

\section{Swelling investigation}

The swelling behaviour of GN-CS hydrogel was studied in distilled water using $1.5 \mathrm{~g}$ of wet GN-CS hydrogel. Fig. 3 shows pictures of hydrogel swelling in water. Using eqn (1), swelling degree of GN-CS hydrogel is calculated to be about $15700.5 \%$ $(157 \mathrm{~g} / \mathrm{g})$ this is a high swelling value compared to previously studied adsorbents.

\section{Adsorption investigation}

The adsorption ability of GN-CS was evaluated using Janus green B (JB) and Congo red (CR). The time-dependent UV-Vis absorption spectra of CR and JB under the adsorption condition in the presence of GN-CS are depicted in Fig. $4 \mathrm{a}$ and b. The absorbance of CR at $495 \mathrm{~nm}$ rapidly decreased as the removal efficiency reached to $100 \%$ after 10 min. In Fig. 4 b, the absorbance of JB at $603 \mathrm{~nm}$ decreased slightly. The maximum removal was noticed at $120 \mathrm{~min}(30 \%)$ further than which it became constant. The results show that GN-CS is a potential absorbent for anionic dyes from aqueous solution. CR was therefore selected for further adsorption study.

\section{Effect of pH}

The adsorption of CR was investigated in the $\mathrm{pH}$ range of 4.010.0 (Fig. $5 \mathrm{a}$ and b). The original $\mathrm{pH}$ of $\mathrm{CR}$ solution was 7.0; the acidic and basic $\mathrm{pH}$ was adjusted by adding of small amounts of $0.1 \mathrm{M} \mathrm{HCl}$ or $\mathrm{NaOH}$ solution. Fig. $5 \mathrm{a}$, shows that maximum adsorption occurred at $\mathrm{pH}$ 7.0. The removal efficiency of CR by $\mathrm{GN}-\mathrm{CS}$ at $\mathrm{pH} 7.0$ is $100 \%$ after $10 \mathrm{~min}$, it is $56.5 \%$ and $70.4 \%$ at $\mathrm{pH} 4.0$ and $\mathrm{pH}$ 10.0, respectively. Structure of the dye molecule at diverse $\mathrm{pH}$ is shown in Fig. 6. $\mathrm{CR}$ is an acidic dye, and in the aqueous medium it is first dissolved and converted to anionic 

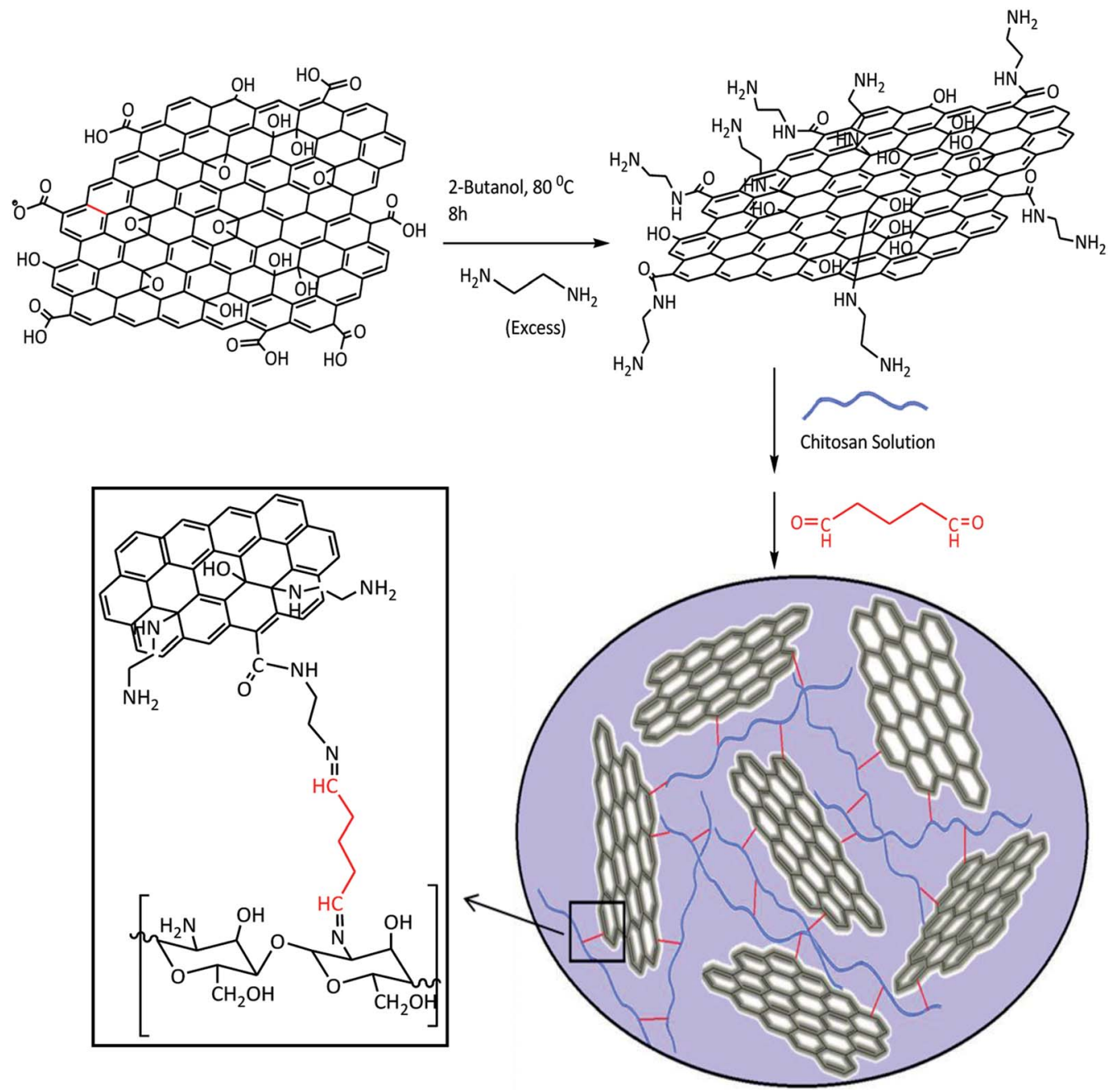

Scheme 1 Synthetic route of GN-CS nanocomposite hydrogel.

(a)

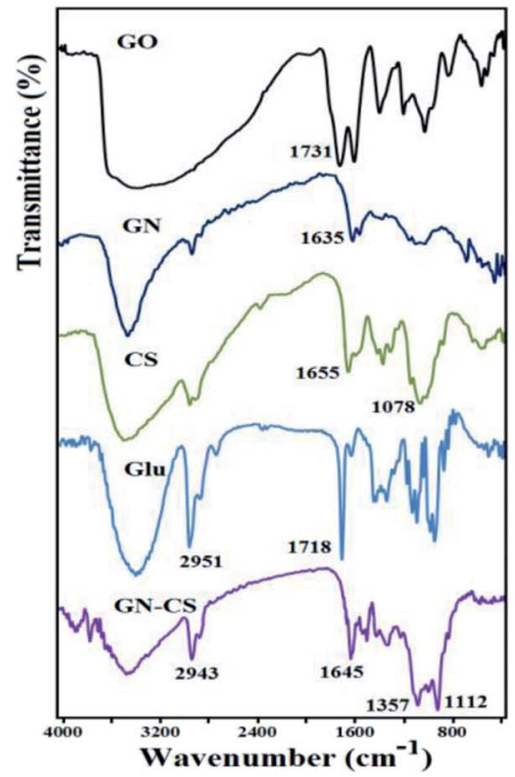

(b)

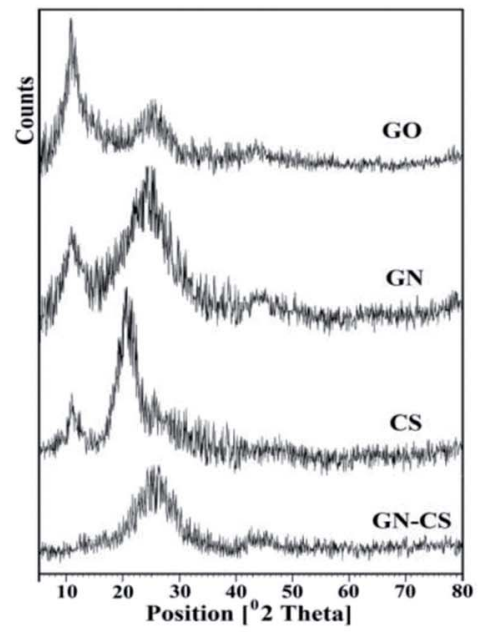

Fig. 1 (a) FT-IR spectra of GO, GN, CS, Glu, and GN-CS. (b) The XRD patterns of GO, GN, CS and GN-CS. 


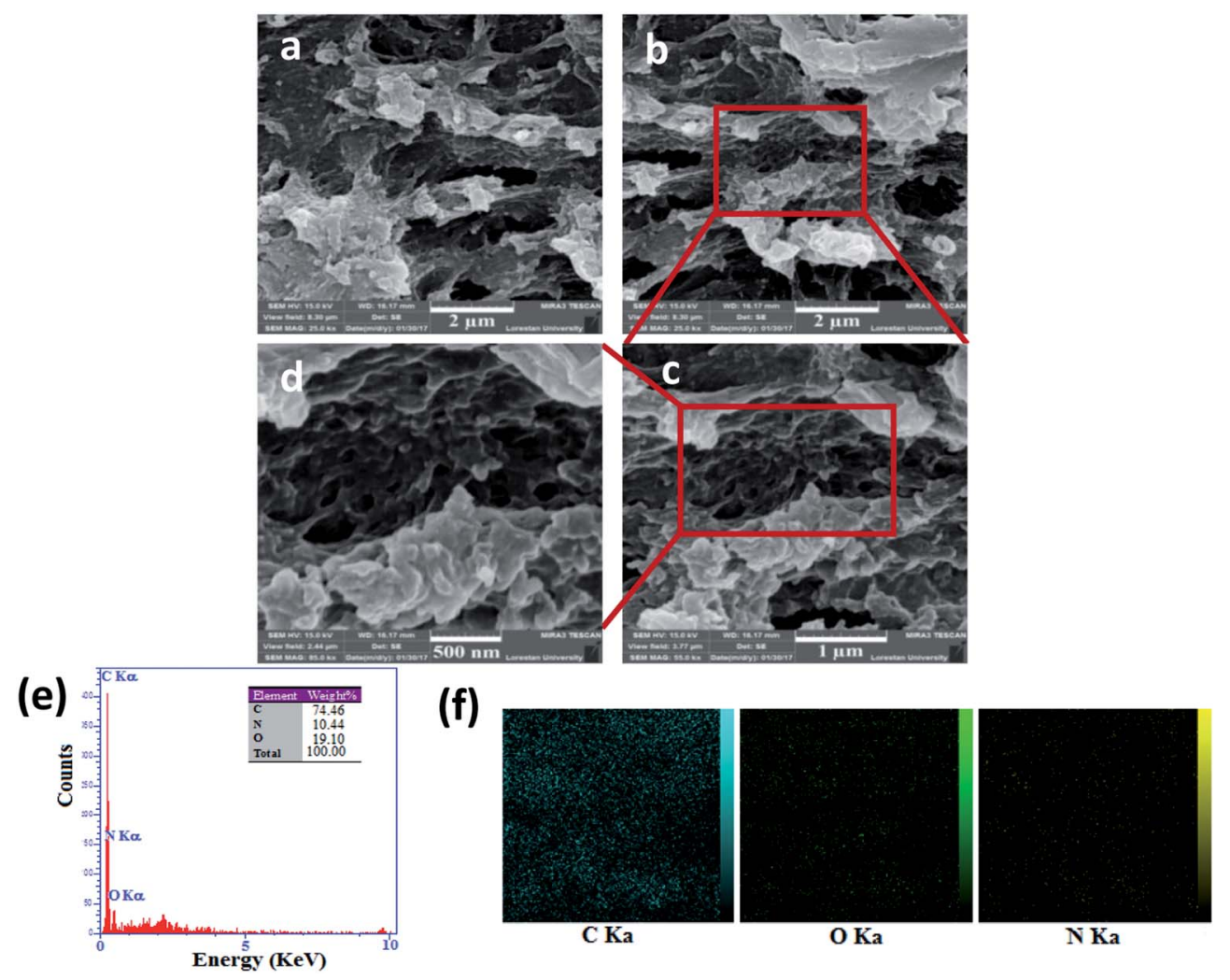

Fig. 2 (a-d) FE-SEM images of GN-CS, (e) EDX spectra and (f) elemental maps of GN-CS.

dye at natural or basic solution while at acidic solution protonated and transformed to cationic dye. At $\mathrm{pH}<7.0$ chitosan is a cationic polymer; also the surface of aminated graphene is positive so that the surface charge of GN-CS is $36.8 \mathrm{mV}$. The adsorption of $\mathrm{CR}$ decreased at $\mathrm{pH} 4.0$ due to the repulsion force between positive charges in protonated CR (Fig. 6b) and surface of GN-CS. At pH above 7.0, the numbers of positive charge in GN-CS decreased $(11.2 \mathrm{mV})$ and the $\mathrm{CR}$ is as anionic form (Fig. 6a) therefore, there is an electrostatic attraction between CR molecules and GO-CS. On the other hand the excess $\mathrm{OH}$ ions at basic $\mathrm{pH}$ compete with the sulfonate groups of $\mathrm{CR}$ and the adsorbed dye is reduced compared to natural $\mathrm{pH}$.

\section{Effect of contact time and concentration of CR}

The time-dependent behavior of CR adsorption over GN-CS was achieved at room temperature. The result is shown in Fig. 7a. The adsorption rate of CR on the aerogel adsorbent was fast for the first 1 min indicating the immediate adsorption of CR and it can be attributed to large surface area and accessibility of active sites of GN-CS aerogel. Fig. 7a is displayed that the equilibrium time for CR is about 10 min under defined conditions and the percentage adsorption is reached to $100 \%$ at this time.

The effect of initial concentration on the adsorption of CR is shown in Fig. 7b. The adsorption capacity raised from 10.0 to $356.0 \mathrm{mg} \mathrm{g}^{-1}$ as the initial CR concentration increased from 5.0 to $500.0 \mathrm{mg} \mathrm{L}^{-1}$. The higher initial concentration offers a higher driving force to overwhelm all mass transfer resistances of CR molecules between the aqueous phase and solid phase. ${ }^{47}$ Table 1 represents the correlation between different parameters of adsorption experiment. The maximum adsorption capacity of GNCS was established to be $356.0 \mathrm{mg} \mathrm{g}^{-1}$ for $500.0 \mathrm{mg} \mathrm{L}^{-1}$ concentration of CR.

\section{Adsorption kinetics}

Adsorption is a physicochemical process that includes the mass transfer of a solute from the liquid phase to the adsorbent's
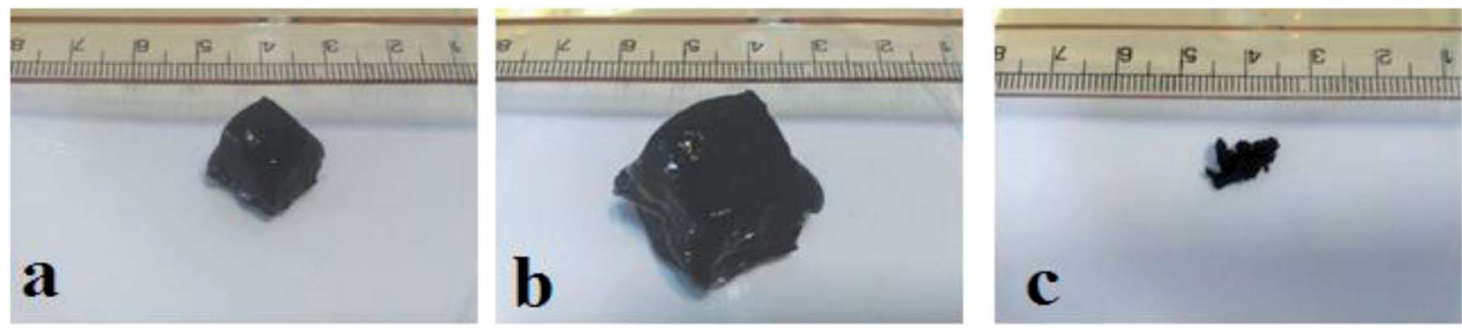

Fig. 3 Photos of (a) wet hydrogel before immersion in water, (b) swollen gel in water and (c) dried gel. 

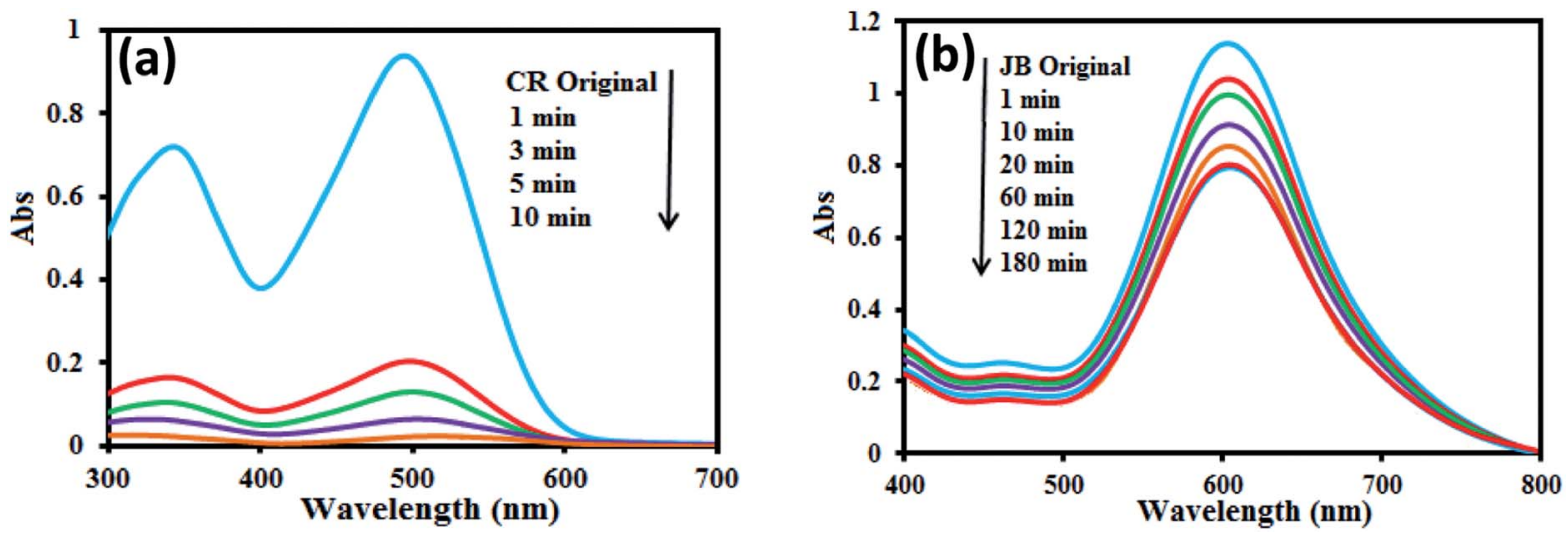

Fig. 4 Time dependent UV-Vis spectra during adsorption of (a) CR and (b) JB, [CR or JB] $=20.0 \mathrm{mg} \mathrm{L}^{-1}$, adsorbent amount $=15.0 \mathrm{mg}, \mathrm{pH} 07.0$.

(a)

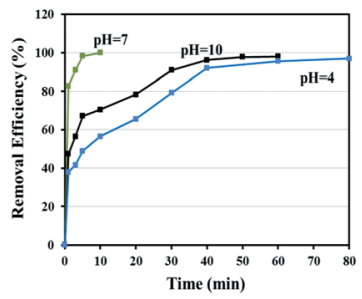

(b)

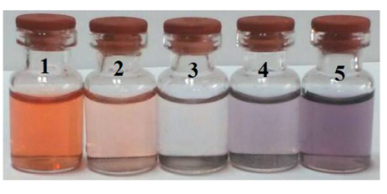

Fig. 5 (a) The effect of initial solution $\mathrm{pH}$ of $\mathrm{CR}$ on removal efficiency. (b) The photos of 1: CR solution $\left(20.0 \mathrm{mg} \mathrm{L}^{-1}\right)$ at natural or basic $\mathrm{pH} ; 2$, 3 and 4: CR solution (20.0 $\mathrm{mg} \mathrm{L}^{-1}$ ) treated with $15.0 \mathrm{mg}$ aerogel after $10 \mathrm{~min}$ at $\mathrm{pH} 10.0,7.0$ and 4.0, respectively and 5: CR solution (20.0 $\mathrm{mg} \mathrm{L}^{-1}$ ) at acidic $\mathrm{pH}$.

surface. $^{48}$ The adsorption kinetics of CR onto GO-CS was studied by four kinetic models including pseudo-first-order, pseudo-second-order, Elovich and intraparticle diffusion. The linear form of pseudo-first order equation ${ }^{49}$ expressed as:

$$
\ln \left(q_{\mathrm{e}}-q_{t}\right)=\ln q_{\mathrm{e} . \mathrm{cal}}-K_{1} t
$$

The parameters of this equation are defined in Table 2. The values of $K_{1}$ and $q_{\text {e.cal }}$ were calculated from slope and intercept of linear curve $\ln \left(q_{\mathrm{e}}-q_{\mathrm{t}}\right)$ vs. $t$ as presented in Fig. 8a and are presented in Table 2 . The correlation coefficient $R^{2}$ for the pseudo-first-order model is 0.964 , and important differences exist between the calculated $q_{\text {e.cal }}\left(26.83 \mathrm{mg} \mathrm{g}^{-1}\right)$ value and experimental $q_{\text {e.exp }}\left(40.0 \mathrm{mg} \mathrm{g}^{-1}\right)$ value. Therefore, the adsorption of Congo red onto GN-CS does not follow the pseudo-firstorder kinetic model.

The pseudo-second-order rate equation ${ }^{50}$ is represented as:

$$
\frac{t}{q_{t}}=\frac{1}{K_{2} q_{\mathrm{e}}^{2}}+\frac{t}{q_{\text {e.cal }}}
$$

The parameters of this equation are defined in Table 2 . The values of $q_{\text {e.cal }}$ and $K_{2}$ were calculated from slope and intercept of linear curve $t / q_{t} v s . t$ as presented in Fig. $8 \mathrm{~b}$ and are presented in Table 2. For the adsorption of Congo red by GN-CS, linear relationships with a high correlation coefficient $\left(R^{2}=0.999\right)$ between $t / q_{t}$ and $t$ indicated that the adsorption process could be fitted by the pseudo-second-order model. Furthermore, for the pseudo-second-order model, the calculated $q_{\text {e.cal }}(41.15 \mathrm{mg}$ $\left.\mathrm{g}^{-1}\right)$ value agree fine with the experimental $q_{\text {e.exp }}\left(40.0 \mathrm{mg} \mathrm{g}^{-1}\right)$ value.

The intraparticle diffusion model ${ }^{51}$ is usually to characterize the rate controlling step, and it is expressed as:

$$
q_{t}=K_{\mathrm{id}} t^{1 / 2}+C_{\mathrm{i}}
$$

The parameters of this equation are defined in Table 2 . The value of $C_{\text {i }}$ gives the information regarding the thickness of the boundary layer. The values of $k_{\mathrm{id}}$ and $C_{\mathrm{i}}$ calculated from slope and intercept of linear curve $q_{t}$ versus $t^{1 / 2}$ as presented in Fig. 8c a)<smiles>Nc1c(N=Nc2ccc(-c3ccc(N=Nc4cc(S(=O)(=O)O[Na])c5ccccc5c4N)cc3)cc2)cc([N+](=O)[O-])c2ccccc12</smiles>

b)<smiles>Nc1c(N=[NH+]c2ccc(-c3ccc([NH+]=Nc4cc(S(=O)(=O)O)c5ccccc5c4N)cc3)cc2)cc(S(=O)(=O)O)c2ccccc12</smiles><smiles></smiles>

Fig. 6 Structure of Congo red at: (a) $\mathrm{pH}>5.5$ and (b) $\mathrm{pH}<5.5$. 
(a)
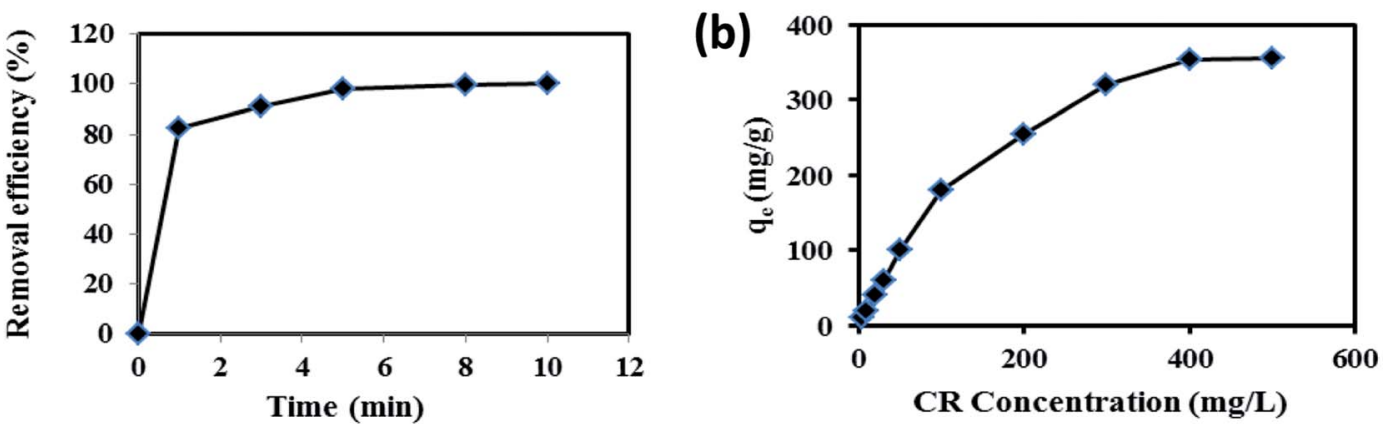

Fig. 7 (a) Effect of contact time on the adsorption capacity (CR solution: $20.0 \mathrm{mg} \mathrm{L}^{-1}, \mathrm{pH} 7.0$, adsorbent dose: $0.015 \mathrm{~g} / 30.0 \mathrm{~mL}$ ). (b) Effect of $\mathrm{CR}$ concentration on the adsorption capacity ( $\mathrm{pH} 7.0$, adsorbent dose: $0.015 \mathrm{~g} / 30.0 \mathrm{~mL}$ ).

and are shown in Table 2. Fig. $8 \mathrm{c}$ shows that the plan did not pass over the origin that indicated the intraparticle diffusion was not the only rate-limiting step and the adsorption of $\mathrm{CR}$ onto GN-CS was a complex process. The initial sharp step is due to the external surface adsorption or instantaneous adsorption stage and the second portion was the gradual adsorption stage. The higher slope of the initial sharp stage showed that the rate was very rapid due to the instantaneous availability of large surface area and active adsorption sites. The lower slope of the second portion indicated a low adsorption rate because of the decreased dye concentration gradient that caused dye molecules to diffuse at long time in the micropores.

The Elovich kinetic equation ${ }^{52}$ is expressed as

$$
q_{t}=\frac{1}{\beta} \ln (\alpha \beta)+\frac{1}{\beta} \ln (t)
$$

The parameters of this equation are defined in Table 2. The values of $\beta$ and $\alpha$ calculated from slope and intercept of the plot of $q_{t}$ versus $\ln t$ as presented in Fig. 8d. The parameters of the Elovich equation were determined and are given in Table 2. The correlation coefficient $R^{2}$ is lower than the pseudo-second-order value. This result designates that Elovich model was unsuitable to represent adsorption kinetic of $\mathrm{CR}$ onto $\mathrm{GN}-\mathrm{CS}$, and the adsorption process was not controlled by chemisorption.

\section{Adsorption isotherm}

Adsorption isotherm represents the distribution of adsorbate between adsorbent and solution at equilibrium. Langmuir, ${ }^{53}$ Freundlich, ${ }^{54}$ Temkin $^{55}$ and Dubinin-Radushkevich (D-R), ${ }^{56}$ four most commonly models, are used to describe the adsorption mechanism more deeply.

The Langmuir model uses a monolayer adsorbate on the surface of the adsorbent, and it is based on the assumption that adsorption occurs on the homogeneous surface, without interactions between the adsorbed dyes molecules. The Langmuir isotherm is given by eqn (8):

$$
\frac{C_{\mathrm{e}}}{q_{\mathrm{e}}}=\frac{1}{q_{\max } K_{\mathrm{L}}}+\frac{C_{\mathrm{e}}}{q_{\max }}
$$

where $q_{\mathrm{e}}\left(\mathrm{mg} \mathrm{g}^{-1}\right)$ is the amount of adsorbate adsorbed on per unit weight of adsorbent, $C_{\mathrm{e}}\left(\mathrm{mg} \mathrm{L}^{-1}\right)$ is the equilibrium concentration of the adsorbate, $q_{\max }\left(\mathrm{mg} \mathrm{g}^{-1}\right)$ and $K_{\mathrm{L}}\left(\mathrm{L} \mathrm{mg}^{-1}\right)$ are Langmuir characteristic constants, which indicates maximum adsorption capacity and the energy of adsorption, respectively.

The values of $q_{\max }$ and $K_{\mathrm{L}}$ were calculated from slope and intercept of linear curve $C_{\mathrm{e}} / q_{\mathrm{e}} v s . C_{\mathrm{e}}$ as presented in Fig. 9a. These parameters were calculated and are given in Table 3 . The value of the correlation coefficient, $R^{2}$, for the fit of isotherm data to Langmuir equation is more close to 1.0 than that for Freundlich, Temkin and D-R equations. Consequently, the experimental equilibrium adsorption data are well explained by the Langmuir equation compared to other models. This suggested the monolayer adsorption of CR dye over the homogeneous surface of GN-CS. The maximum adsorption capacity of GN-CS for Congo red calculated from the Langmuir equation is $384.62 \mathrm{mg} \mathrm{g}^{-1}$ and listed in Table 4 with literature values of $q_{\max }$ of other adsorbents for CR adsorption. Comparing the obtained results demonstrates a high adsorption capacity of GN-CS aerogel for Congo red.

The Langmuir isotherm can be declared in terms of a dimensionless equilibrium parameter which is calculated using eqn (9).

$$
R_{\mathrm{L}}=\frac{1}{1+K_{\mathrm{L}} C_{0}}
$$

where $R_{\mathrm{L}}$ is the separation factor, and $C_{0}\left(\mathrm{mg} \mathrm{L}^{-1}\right)$ is the initial concentration of dye. Separation factor $R_{\mathrm{L}}$ shows the feasibility of Langmuir isotherm, $r<1$ shows favorable adsorption and $r>$

\begin{tabular}{|c|c|c|c|c|c|c|c|c|c|c|}
\hline CR concentration $\left(\mathrm{mg} \mathrm{L}^{-1}\right)$ & 5.0 & 10.0 & 20.0 & 30.0 & 50.0 & 100.0 & 200.0 & 300.0 & 400.0 & 500.0 \\
\hline $\mathrm{RE}(\%)$ & 100 & 100 & 100 & 100 & 100 & 90.6 & 63.57 & 53.2 & 44.1 & 35.6 \\
\hline Equilibrium time (min) & 3 & 5 & 10 & 50 & 100 & 480 & 600 & 720 & 1200 & 1440 \\
\hline$q_{\mathrm{e}}\left(\mathrm{mg} \mathrm{g}^{-1}\right)$ & 10.0 & 20.0 & 40.0 & 60.0 & 100.0 & 181.2 & 254.27 & 319.2 & 352.8 & 356.0 \\
\hline
\end{tabular}

Table 1 Correlation between initial CR concentration, removal efficiency (RE\%) of CR, equilibrium time and adsorption capacity $\left(q_{\mathrm{e}}\right.$ ) of GN-CS (adsorbent dose: $0.015 \mathrm{~g} / 30.0 \mathrm{~mL}$ ) 
Table 2 Kinetic parameters for the adsorption of CR by GN-CS at the equilibrium time (10 min)

\begin{tabular}{|c|c|c|c|}
\hline Model & parameters & Definition & Values \\
\hline \multirow[t]{3}{*}{ Pseudo-first-order } & $q_{\text {e.exp }}\left(\mathrm{mg} \mathrm{g}^{-1}\right)$ & Experimental adsorption capacity at equilibrium & 40.0 \\
\hline & $q_{\text {e.cal }}\left(\mathrm{mg} \mathrm{g}^{-1}\right)$ & Calculated adsorption capacity & 26.83 \\
\hline & $R^{2}$ & Correlation coefficient & 0.964 \\
\hline \multirow[t]{2}{*}{ Pseudo-second-order } & $q_{\text {e.cal }}\left(\mathrm{mg} \mathrm{g}^{-1}\right)$ & Calculated adsorption capacity & 41.15 \\
\hline & $K_{2}\left(\mathrm{~g} \mathrm{mg}^{-1} \min ^{-1}\right)$ & Rate constant & 0.088 \\
\hline & $\beta\left(\mathrm{g} \mathrm{mg}^{-1}\right)$ & Related to activation energy for chemisorption & 0.310 \\
\hline & $R^{2}$ & Correlation coefficient & 0.962 \\
\hline \multirow[t]{4}{*}{ Intraparticle diffusion } & $C_{1}$ & Intercept at stage i & 3.480 \\
\hline & $K_{\mathrm{id}, 1}\left(\mathrm{mg} \mathrm{g}^{-1} \min ^{1 / 2}\right)$ & Rate constant & 21.638 \\
\hline & $R_{1}^{2}$ & Correlation coefficient & 0.881 \\
\hline & $C_{2}$ & Intercept at stage i & 32.881 \\
\hline
\end{tabular}

1 is an unfavorable process. Values of $R_{\mathrm{L}}$ are listed in Table 3, and all are between 0 and 0.2 demonstrating favorable adsorption of dye onto the GN-CS. The $\pi-\pi$ stacking between $\mathrm{CR}$ and aromatic structure of GN, hydrogen bonding between sulfonate and amine groups from CR with amine and imine groups of GN-CS and the electrostatic interactions between the negatively charged sulfonate functional groups on CR and positively charged adsorbent may also play a significant role in the adsorption process.

The Freundlich model assumes that adsorption occurs in the heterogeneous surface and it is expressed by eqn (10):

$$
\ln q_{\mathrm{e}}=\ln K_{\mathrm{F}}+\frac{1}{n} \ln C_{\mathrm{e}}
$$

where, $K_{\mathrm{F}}\left[\mathrm{mg} \mathrm{g}^{-1}\left(\mathrm{~L} \mathrm{mg}^{-1}\right)^{-1 / n}\right]$ and $1 / n$ are Freundlich characteristic constants representing adsorption capacity and adsorption intensity respectively. The values of $K_{\mathrm{F}}$ and $1 / n$ were computed from the intercept and slope of linear curve $\ln q_{\mathrm{e}} v s$. $\ln C_{\mathrm{e}}$ as presented in Fig. 9b and listed in Table 3 . In the Freundlich isotherm model, the value of $n$ indicates the type of isotherm. When $n$ is equal to 1.0 , the adsorption is linear. Additional, $n$ below unity shows that adsorption is a chemical
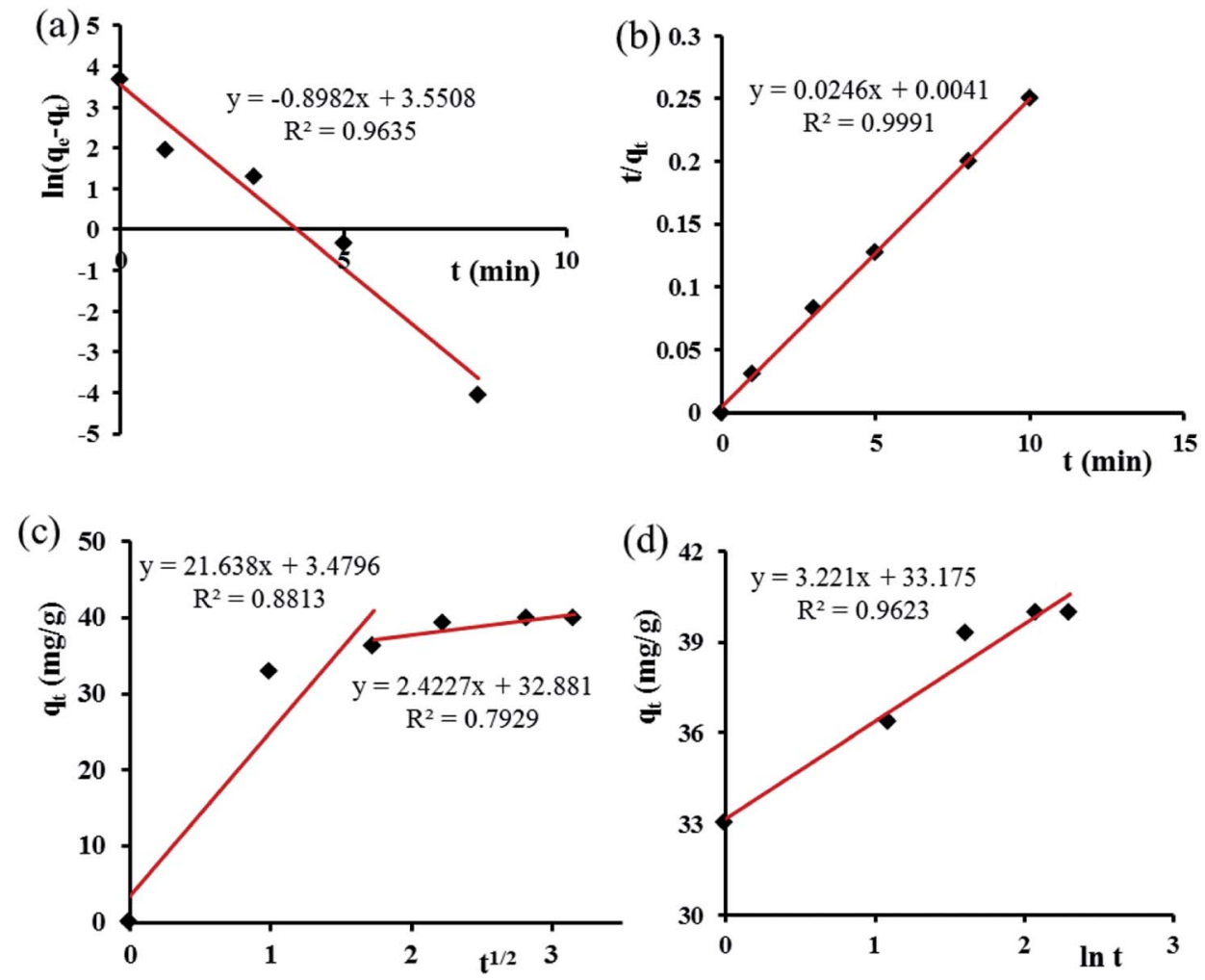

Fig. 8 (a) Pseudo-first-order, (b) pseudo-second-order, (c) intraparticle diffusion and (d) Elovich models for adsorption of CR over GN-CS. 

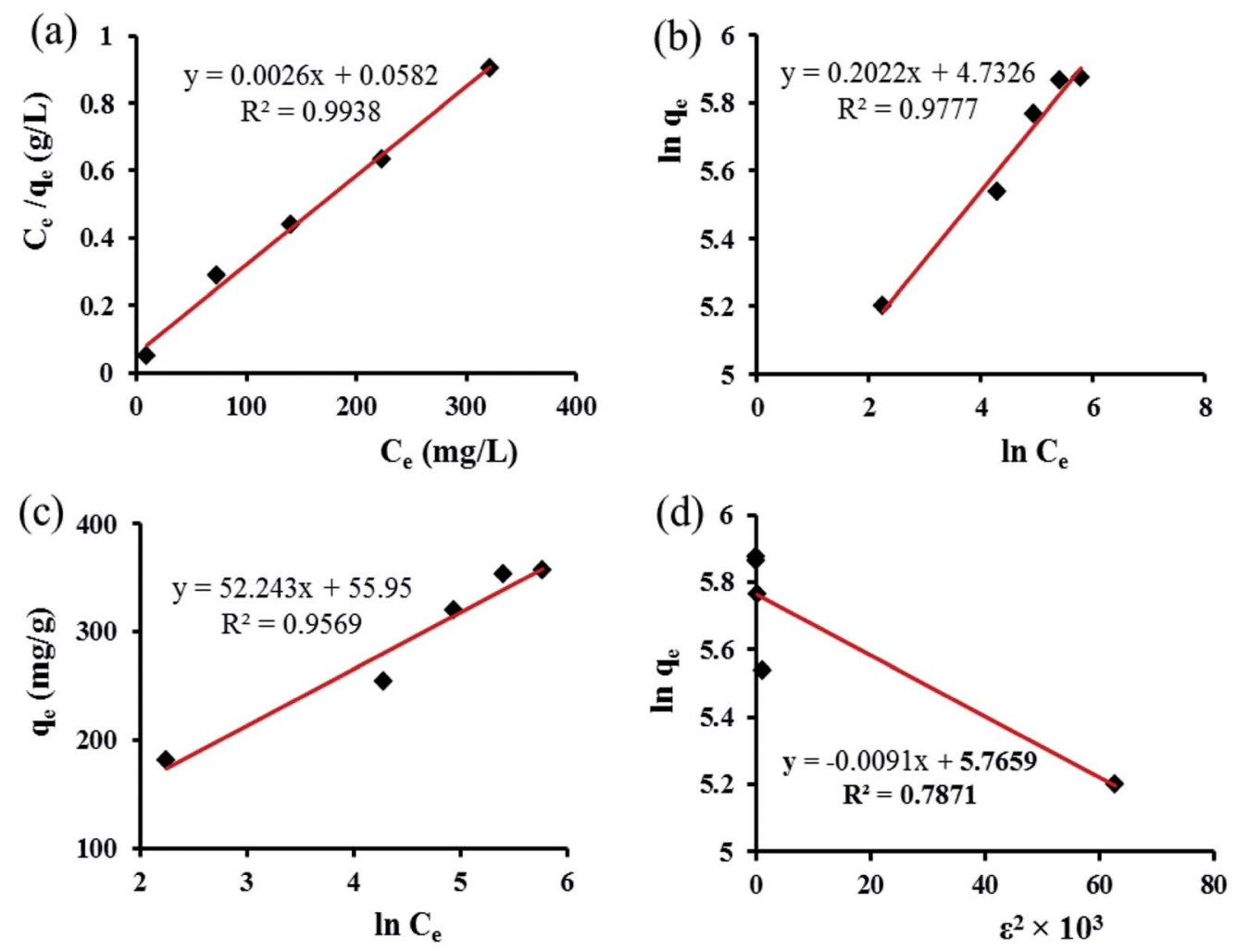

Fig. 9 (a) Langmuir, (b) Freundlich, (c) Temkin and (d) Dubinin-Radushkevich adsorption isotherms for CR on GN-CS.

Table 3 Isotherm parameters for the adsorption of CR by GN-CS

\begin{tabular}{lll}
\hline Isotherm model & Parameters & Value \\
\hline Langmuir & $q_{\max }\left(\mathrm{mg} \mathrm{g}^{-1}\right)$ & 384.62 \\
& $K_{\mathrm{L}}\left(\mathrm{L} \mathrm{mg}^{-1}\right)$ & 0.0447 \\
& $R_{\mathrm{L}}$ & $0.0428-0.1828$ \\
& $R^{2}$ & 0.9938 \\
Freundlich & $K_{\mathrm{F}}\left(\mathrm{L} \mathrm{mg}^{-1}\right)$ & 113.59 \\
& $n$ & 4.9456 \\
\multirow{2}{*}{ Temkin } & $R^{2}$ & 0.9777 \\
& $k_{0}\left(\mathrm{~L} \mathrm{mg}^{-1}\right)$ & 2.9182 \\
D-R & $\Delta Q\left(\mathrm{~J} \mathrm{~mol}^{-1}\right)$ & 47.424 \\
& $R^{2}$ & 0.9569 \\
& $q_{\mathrm{D}}\left(\mathrm{mg} \mathrm{g}^{-1}\right)$ & 319.226 \\
& $K_{\mathrm{D}}\left(\mathrm{mol}^{2} \mathrm{~J}^{-2}\right)$ & $9.1 \times 10^{-3}$ \\
$E\left(\mathrm{~kJ} \mathrm{~mol}^{-1}\right)$ & 7.4125 \\
$R^{2}$ & 0.7871
\end{tabular}

process; while, $n$ above unity is connected with favorable adsorption and a physical process. The values of $n$ are larger than 1 ( $n=$ 4.946), indicating that CR is favorably adsorbed by GN-CS.

The Temkin isotherm model has expected that the heat of adsorption of all the dye molecules in the layer declines linearly with coverage due to adsorbate-adsorbate interactions. The linear form of Temkin isotherm model given as:

$$
q_{\mathrm{e}}=B \ln k_{0}+B \ln C_{\mathrm{e}}
$$

where $B=R T / \Delta Q, \Delta Q=(-\Delta H)$ is Temkin isotherm constant $(\mathrm{J}$ $\left.\mathrm{mol}^{-1}\right), R$ is the gas constant $\left(8.314 \mathrm{~J} \mathrm{~mol}^{-1} \mathrm{~K}^{-1}\right), T$ is the
Table 4 Adsorption capacities of CR dye on chitosan or graphenebased adsorbents

\begin{tabular}{|c|c|c|}
\hline Type of adsorbent & $q_{\max }\left(\mathrm{mg} \mathrm{g}^{-1}\right)$ & Reference \\
\hline $\mathrm{Co} / \mathrm{G}$ & 934.9 & 41 \\
\hline CS/CTAB & 433.12 & 25 \\
\hline $\mathrm{CS} / \mathrm{CNT}$ & 405.4 & 26 \\
\hline CS/TX-100 & 378.79 & 24 \\
\hline $\mathrm{CS} / \mathrm{GO}$ & 370.37 & 42 \\
\hline CS/SDS beads & 318.47 & 24 \\
\hline GO/CS/ETCH & 294.12 & 43 \\
\hline CS beads & 223.25 & 25 \\
\hline Magnetic GO & 143.60 & 33 \\
\hline $\mathrm{NiO} /$ graphene & 123.89 & 34 \\
\hline $\mathrm{GO} / \mathrm{Fe}_{3} \mathrm{O}_{4}$ & 98.8 & 35 \\
\hline $\mathrm{Fe}_{3} \mathrm{O}_{4} @ \mathrm{mTiO}_{2} @ \mathrm{GO}$ & 89.95 & 36 \\
\hline CS/montmorillonite & 74.73 & 37 \\
\hline $\mathrm{Fe}_{3} \mathrm{O}_{4} @ g r a p h e n e$ & 33.66 & 38 \\
\hline Chitosan resins & 32.11 & 39 \\
\hline $\begin{array}{l}\mathrm{GO} / \text { polyacrylamide } \\
\text { hydrogel }\end{array}$ & 8.0 & 40 \\
\hline GN-CS aerogel & 384.62 & This work \\
\hline
\end{tabular}

absolute temperature $(\mathrm{K})$, and $k_{0}$ is the equilibrium binding constant $\left(\mathrm{L} \mathrm{mg}^{-1}\right)$. The values of $\Delta Q$ and $k_{0}$ can be computed from the slope and intercept of the plot of $q_{\mathrm{e}}$ versus $\ln C_{\mathrm{e}}$ as presented in Fig. 9b and listed in Table 3. The variation of adsorption energy, $\Delta Q=(-\Delta H)$, is positive which suggests that the adsorption is an exothermic process.

The $\mathrm{D}-\mathrm{R}$ model is generally used to differentiate between physical and chemical adsorption and its linear form is given as: 


$$
\ln q_{\mathrm{e}}=\ln q_{\mathrm{D}}-K_{\mathrm{D}} \varepsilon^{2}
$$

where $q_{\mathrm{e}}$ is the amount of the dye adsorbed per unit weight of the adsorbent in $\left(\mathrm{mg} \mathrm{g}^{-1}\right), q_{\mathrm{D}}$ is the $\mathrm{D}-\mathrm{R}$ adsorption capacity $\left(\mathrm{mg} \mathrm{g}^{-1}\right)$, and $K_{\mathrm{D}}$ is a constant related to adsorption energy $\left(\mathrm{mol}^{2} \mathrm{~J}^{-2}\right), \varepsilon$ the Polanyi potential calculated from the eqn (13):

$$
\varepsilon=R T \ln \left(1+\frac{1}{C_{\mathrm{e}}}\right)
$$

The values of $q_{\mathrm{D}}$ and $K_{\mathrm{D}}$ can be computed from the slope and intercept of the plot of $\ln q_{\mathrm{e}}$ against $\varepsilon^{2}$. The constant $K_{\mathrm{D}}$ gives valuable information about the mean free energy $E\left(\mathrm{~kJ} \mathrm{~mol}^{-1}\right)$ of adsorption per molecule of adsorbate and it can be calculated using the following relationship:

$$
E=\frac{1}{\sqrt{2 K_{\mathrm{D}}}}
$$

The value of $E$ is valuable for appraising the type of adsorption process. When $E<8.0 \mathrm{~kJ} \mathrm{~mol}^{-1}$, the adsorption type can be described by physical adsorption. ${ }^{56}$ In this study, the value of $E$ was $7.41 \mathrm{~kJ} \mathrm{~mol}^{-1}$, suggested that adsorption process of CR onto adsorbent is a physical-sorption process.

\section{Reusability study}

In reusability study, $0.015 \mathrm{~g}$ of GN-CS was used for adsorption of $20.0 \mathrm{mg} \mathrm{L}^{-1}$ CR solution (30.0 mL). Remarkably GN-CS absolutely removes $20.0 \mathrm{mg} \mathrm{L}^{-1}$ of $\mathrm{CR}$ at first cycle. CR molecules were desorbed completely from adsorbents after repeated washing with $4: 1$ solution of EtOH : DMF three times. Then, the adsorbent was dried at $70^{\circ} \mathrm{C}$ before reused for the next adsorption. The results are displayed in Fig. 10 that shows the efficiency of dye removal was $100 \%$ after three cycles, so the as-prepared adsorbent is reusable.

\section{Removal of CR dye with GN and GO}

To further demonstrate the role of graphene nanosheets and surface charge in adsorption, GN and GO were individually tested for removing the CR dye. For this purpose, $0.015 \mathrm{~g}$ of GN

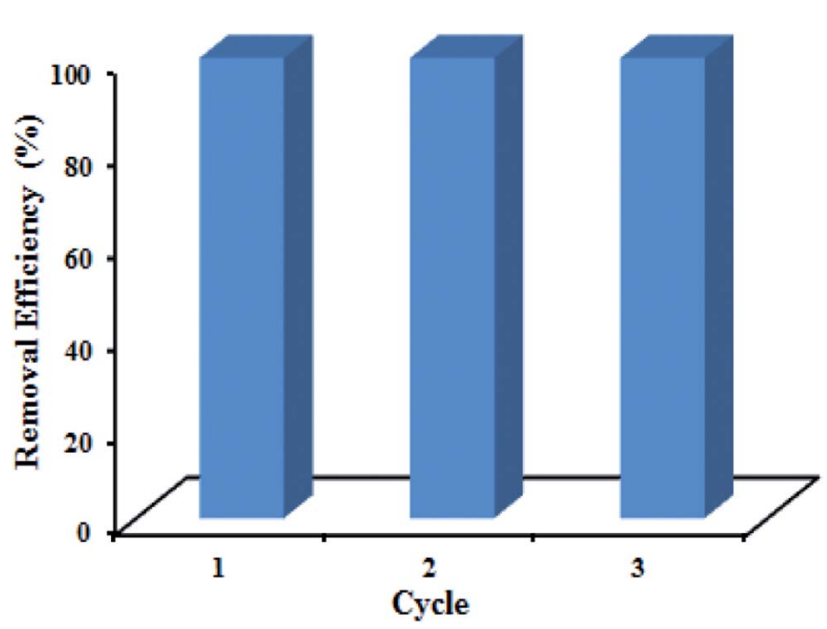

Fig. 10 Recycling test of GN-CS toward CR adsorption.

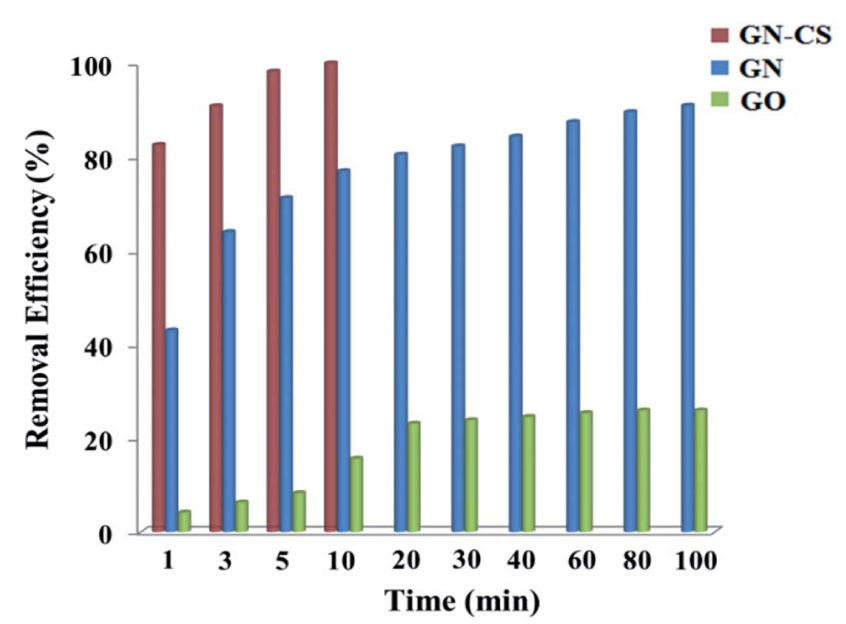

Fig. 11 Removal efficiency of GO, GN and GN-CS toward CR adsorption at different times.

or GO was used for adsorption of $20.0 \mathrm{mg} \mathrm{L}^{-1}$ CR dye solution $(30.0 \mathrm{~mL})$ at $\mathrm{pH}$ 7.0. The removal efficiency of GN-CS, GN, and GO over time is displayed in Fig. 11. The results indicated that the nanosheets of GN have a significant potential for color adsorption but at a much lower rate than GN-CS. While the removal efficiency of GN-CS reaches to $100 \%$ in 10 minutes, this value is $91 \%$ and $26 \%$ over $100 \mathrm{~min}$ for GN and GO, respectively. The result indicates that GO is not suitable adsorbent for CR dye that it can be attributed to repulsion interactions between negative charges of CR dye molecules and GO.

\section{Conclusion}

The nanocomposite hydrogel was prepared by using low-toxic and cost-effective precursors in mild condition under 60 second time. GN sheets and CS chains are crosslinked by glutaraldehyde, forming a 3D network. The GN-CS aerogel that obtained by freeze-drying of the hydrogel were used to remove organic dyes. The equilibrium studies reveal a pseudo-secondorder kinetic model and Langmuir isotherm model was best fitted. The maximum dye adsorption capacity calculated from the Langmuir isotherm equation was $384.62 \mathrm{mg} \mathrm{g}^{-1}$. Moreover, the aerogel was stable and easily recovered. Simple and rapid synthesis, high absorbance capacity, absorption kinetics and recyclability of the GN-CS aerogel indicate good potential for industrial applications.

\section{Conflicts of interest}

There are no conflicts of interest.

\section{Acknowledgements}

The authors are grateful to the Lorestan University for financial support of this work. 


\section{References}

1 M. Vakili, M. Rafatullah, B. Salamatinia, A. Z. Abdullah, M. H. Ibrahim, K. B. Tan, Z. Gholami and P. Amouzgar, Carbohydr. Polym., 2014, 113, 115-130.

2 A. Gottlieb, C. Shaw, A. Smith, A. Wheatley and S. Forsythe, J. Biotechnol., 2003, 101, 49-56.

3 P. Frid, S. V. Anisimov and N. Popovic, Brain Res. Rev., 2007, 53, 135-160.

4 E. Y. Ozmen and M. Yilmaz, J. Hazard. Mater., 2007, 148, $303-$ 310.

5 G. Mezohegyi, F. P. van der Zee, J. Font, A. Fortuny and A. Fabregat, J. Environ. Manage., 2012, 102, 148-164.

6 S. Wang, C. W. Ng, W. Wang, Q. Li and Z. Hao, Chem. Eng. J., 2012, 197, 34-40.

7 H. W. Liang, X. Cao, W. J. Zhang, H. T. Lin, F. Zhou, L. F. Chen and S. H. Yu, Adv. Funct. Mater., 2011, 21, 38513858.

8 A. K. Geim and K. S. Novoselov, Nat. Mater., 2007, 6, 183-191. 9 C. N. R. Rao, A. K. Sood, K. S. Subrahmanyam and A. Govindaraj, Angew. Chem., Int. Ed., 2009, 48, 7752-7777.

10 T.-T. Tang, Y. Zhang, C.-H. Park, B. Geng, C. Girit, Z. Hao, M. C. Martin, A. Zettl, M. F. Crommie and S. G. Louie, Nat. Nanotechnol., 2010, 5, 32-36.

11 R. K. Paul, M. Ghazinejad, M. Penchev, J. Lin, M. Ozkan and C. S. Ozkan, Small, 2010, 6, 2309-2313.

12 Z. Liu, J. T. Robinson, X. Sun and H. Dai, J. Am. Chem. Soc., 2008, 130, 10876-10877.

13 O. Akhavan and E. Ghaderi, ACS Nano, 2010, 4, 5731-5736.

14 S. Omidi, A. Kakanejadifard and F. Azarbani, J. Mol. Liq., 2017, 242, 812-821.

15 M. D. Stoller, S. Park, Y. Zhu, J. An and R. S. Ruoff, Nano Lett., 2008, 8, 3498-3502.

16 S. Park, K.-S. Lee, G. Bozoklu, W. Cai, S. T. Nguyen and R. S. Ruoff, ACS Nano, 2008, 2, 572-578.

17 Y. Xu, Q. Wu, Y. Sun, H. Bai and G. Shi, ACS Nano, 2010, 4, 7358-7362.

18 W. Zhang, C. Zhou, W. Zhou, A. Lei, Q. Zhang, Q. Wan and B. Zou, Bull. Environ. Contam. Toxicol., 2011, 87, 86.

19 Y. Chang, S.-T. Yang, J.-H. Liu, E. Dong, Y. Wang, A. Cao, Y. Liu and H. Wang, Toxicol. Lett., 2011, 200, 201-210.

20 V. C. Sanchez, A. Jachak, R. H. Hurt and A. B. Kane, Chem. Res. Toxicol., 2011, 25, 15-34.

21 H. Sereshti, S. Samadi, S. Asgari and M. Karimi, $R S C A d v$, 2015, 5, 9396-9404.

22 Z. Dong, D. Wang, X. Liu, X. Pei, L. Chen and J. Jin, J. Mater. Chem. A, 2014, 2, 5034-5040.

23 J. Liu, K. Zhu, T. Jiao, R. Xing, W. Hong, L. Zhang, Q. Zhang and Q. Peng, Colloids Surf., A, 2017, 529, 668-676.

24 S. Chatterjee, D. S. Lee, M. W. Lee and S. H. Woo, Bioresour. Technol., 2009, 100, 3862-3868.

25 S. Chatterjee, D. S. Lee, M. W. Lee and S. H. Woo, Bioresour. Technol., 2009, 100, 2803-2809.

26 S. Chatterjee, M. W. Lee and S. H. Woo, Bioresour. Technol., 2010, 101, 1800-1806.
27 Y. Chen, L. Chen, H. Bai and L. Li, J. Mater. Chem. A, 2013, 1, 1992-2001.

28 L. Gan, S. Shang, E. Hu, C. W. M. Yuen and S.-x. Jiang, Appl. Surf. Sci., 2015, 357, 866-872.

29 J. Deng, B. Lei, A. He, X. Zhang, L. Ma, S. Li and C. Zhao, J. Hazard. Mater., 2013, 263, 467-478.

30 L. Wang, J. Li, C. Mao, L. Zhang, L. Zhao and Q. Jiang, Dalton Trans., 2013, 42, 8070-8077.

31 M. A. Kamal, S. Bibi, S. W. Bokhari, A. H. Siddique and T. Yasin, React. Funct. Polym., 2017, 110, 21-29.

32 Q. Du, J. Sun, Y. Li, X. Yang, X. Wang, Z. Wang and L. Xia, Chem. Eng. J., 2014, 245, 99-106.

33 X.-r. Zhang, J.-l. Gong, G.-m. Zeng and J.-h. Deng, China Environ. Sci., 2013, 33, 1379-1385.

34 X. Rong, F. Qiu, J. Qin, H. Zhao, J. Yan and D. Yang, J. Ind. Eng. Chem., 2015, 26, 354-363.

35 M. Namvari and H. Namazi, Int. J. Environ. Sci. Technol., 2014, 11, 1527-1536.

36 L. Li, X. Li, H. Duan, X. Wang and C. Luo, Dalton Trans., 2014, 43, 8431-8438.

37 L. Wang and A. Wang, J. Hazard. Mater., 2007, 147, 979-985.

38 Y. Yao, S. Miao, S. Liu, L. P. Ma, H. Sun and S. Wang, Chem. Eng. J., 2012, 184, 326-332.

39 L.-X. Zeng, Y.-F. Chen, Q.-Y. Zhang, Y. Kang and J.-W. Luo, Desalin. Water Treat., 2014, 52, 7733-7742.

40 W. Cui, J. Ji, Y.-F. Cai, H. Li and R. Ran, J. Mater. Chem. A, 2015, 3, 17445-17458.

41 S. Wang, X. Li, Y. Liu, C. Zhang, X. Tan, G. Zeng, B. Song and L. Jiang, J. Hazard. Mater., 2018, 342, 177-191.

42 B. Y. Z. Hiew, L. Y. Lee, X. J. Lee, S. Thangalazhy-Gopakumar, S. Gan, S. S. Lim, G.-T. Pan, T. C.-K. Yang, W. S. Chiu and P. S. Khiew, Process Saf. Environ. Prot., 2018, 116, 262-286.

43 D. C. Marcano, D. V. Kosynkin, J. M. Berlin, A. Sinitskii, Z. Sun, A. Slesarev, L. B. Alemany, W. Lu and J. M. Tour, ACS Nano, 2010, 4, 4806-4814.

44 B. Xue, J. Zhu, N. Liu and Y. Li, Catal. Commun., 2015, 64, 105-109.

45 N. H. Kim, T. Kuila and J. H. Lee, J. Mater. Chem. A, 2013, 1, 1349-1358.

46 R. J. Samuels, J. Polym. Sci., Part B: Polym. Phys., 1981, 19, 1081-1105.

47 G. A. Sayğılı, J. Mol. Liq., 2015, 211, 515-526.

48 H. Zhu, R. Jiang, L. Xiao and G. Zeng, Bioresour. Technol., 2010, 101, 5063-5069.

49 K. Santhy and P. Selvapathy, Bioresour. Technol., 2006, 97, 1329-1336.

50 Y.-S. Ho and G. McKay, Process Biochem., 1999, 34, 451-465.

51 A. Kausar, H. N. Bhatti and G. MacKinnon, Colloids Surf., B, 2013, 111, 124-133.

52 N. A. Oladoja and A. L. Ahmad, Sep. Purif. Technol., 2013, 116, 230-239.

53 I. Langmuir, J. Am. Chem. Soc., 1918, 40, 1361-1403.

54 H. Freundlich, Z. Phys. Chem., 1907, 57, 385-470.

55 S. J. Allen, Q. Gan, R. Matthews and P. A. Johnson, Bioresour. Technol., 2003, 88, 143-152.

56 C. Abasi, A. Abia and J. Igwe, Environ. Res. J., 2011, 5, 104113. 